\title{
Some Perpetually Old and New Development Issues in the EU Regions: Competitiveness, Resilience, and Convergence: Where Do the New Member States Stand?
}

\author{
Marioara Iordan and Mihaela-Nona Chilian \\ Additional information is available at the end of the chapter
}

http://dx.doi.org/10.5772/intechopen.70645

\begin{abstract}
Competitiveness, resilience, and convergence were topics that for decades were listed among the hot issues that have animated the scientific and political debates in the area of economic growth and economic development. For the new member states (NMS) of the European Union, which have accessed the Union since 2004, competitiveness and cohesion became from the first days of their EU membership key topics on their national policy agendas, both as directives of the EU policies to be transposed and implemented nationally and as genuine domestic concerns to be addressed by each of the NMS, while resilience revealed its importance a little bit later, on the occasion of the global economic crisis of 2008-2010 and subsequent recession. Considering their importance for the current and future socioeconomic development of the new member states, the authors present and briefly analyze the topics of competitiveness, resilience, and cohesion in a joint framework, at regional level, based on their common roots within the economic growth and development theories, with the help of a minimal, but powerful, set of relevant indicators, over three significant recent periods: ante-crisis, crisis, and post-crisis. The findings point toward both different and similar competitiveness, resilience, and convergence developments within the new member states and across countries, regions, and periods, also revealing growth and adaptation patterns similar to those found in the more developed regions and countries of the EU, especially in the wake of the global economic crisis.
\end{abstract}

Keywords: regional competitiveness, regional resilience, convergence, new member states, GDP per capita, productivity, employment, growth and development patterns, adaptation 


\section{Introduction}

Competitiveness, resilience, and convergence: irrespective their ordering, such topics were found for decades among the hot issues (however, not exclusive) that have animated the scientific and political debates in the area of economic growth and economic development, especially in the European Union but also worldwide. The entire policies and programs were explicitly dedicated to them, for instance, the Lisbon Strategy of the European Union during the 2000-2010 period, with its explicit (and overambitious) goal of making the EU the most competitive territory of the world. Under new forms, these topics reemerged as foundations of the current Europe 2020 Strategy, with its emphasis on smart, sustainable, and inclusive growth, and objectives, targets, and indicators of the previous more explicit policies are included among the instruments of the policies implemented during this programming period in the EU and its member states. In the same line of argument, newer approaches on competitiveness, resilience, and convergence appeared in the economic science or older ones were upgraded, data bases were updated and improved, and new techniques were employed to solve increasingly complex and interdisciplinaryrelated topics.

For the new member states (NMS henceforth) of the EU, which have accessed the Union since 2004, competitiveness and cohesion were from the first days of their EU membership key topics on their national policy agendas, both as directives of the EU policies to be transposed and implemented nationally and as genuine domestic concerns to be addressed by each of the NMS. Resilience revealed its importance a little bit later, with the onset of the global economic crisis of 2008-2010 and subsequent recession, whose impacts were severe and still not fully accommodated by the more stressed socioeconomic systems of the NMS, barely emerged from the labors of transition to the market economy. With the advance of the environmental and sustainability issues, resilience itself follows the same path of "perpetuation," explicitly or under different (interdisciplinary) forms, within the current topics approached and analyzed in the socioeconomic science and in policy making. All the abovementioned topics of interest were broadly analyzed and debated at national level in the EU and the NMS, but a special interest raised their "territorial detailing" and "descent into the real economy": analysis and/or enforcement at regional, subregional, and local levels.

Considering such ideas, the authors present and briefly analyze the topics of competitiveness, resilience, and cohesion not individually, but jointly, not at national, but at regional level (a more detailed level of analysis needing more writing space), based on their common roots within the economic growth and development theories, with the view to outline an integrated framework of analysis. The analysis is far from comprehensive and focuses entirely on the NMS in their relationships with competitiveness, resilience, and convergence. The paper is organized as follows. Part 2 briefly presents the definitions and some conceptual issues regarding competitiveness, resilience, and convergence; Part 3 presents a literature review on the assessment methodologies and indicators; Part 4 shows the results of the chosen assessment framework; and Part 5 outlines conclusions and further lines of research. 


\section{Regional competitiveness, resilience, and convergence: definitions and some conceptual issues}

Competitiveness is a topic that animates for years both the scientific and the political arenas, with extensive and often controversial debates covering a wide range of economic approaches, from those originating at company and industry level to those that include international trade and, not least, the location, with connections to different streams of economic theory, from Porter's cluster theory to the theories of new economic geography and regional economy, whose roots may be found in the works of P. Krugman (see [1]). Competitiveness is also one of the central interests of the economic policy concerned with the welfare of nations, because the long-term life standard of every nation depends on the ability of the national economy to achieve and maintain a high level of productivity in those sectors and companies that are competitive on the international markets [2]. Nationally, competitiveness involves a territorial dimension, the localization of competitive economic agents being usually concentrated within certain areas of the national territory.

Regional competitiveness is a topic of major interests among the decision makers of the European Union and of the member states, lately especially in connection with the economic and social cohesion and the consequent policies. Increasing competitiveness of the laggard and less prosperous regions of Europe is a key for achieving the goal of cohesion, especially in the context of the monetary union and of integration of the new member states [3], which, in their turn, induced new theoretical approaches in economics that assign a fundamental place to the localization of economic activities and to the development of regional economies [4]. Moreover, the achievement of Europe 2020 goals regarding the smart, sustainable, and inclusive growth has depended, depends, and to a great extent will depend on the situation of the European regions, and according to the EU vision, the competitive regions are those regions able to anticipate and successfully adapt to the domestic and foreign economic and social challenges [5]. However, despite the long-term implementation of the EU regional policy, the existing regional disparities continue to pose problems in terms of cohesion in the EU, especially after its eastward expansion and the 2008-2010 economic crisis.

Different concepts of regional competitiveness, stemming from different opinions, were revealed over years in the theory and practice of economic growth and economic development. Basically, the notion of regional competitiveness captures two different economic categories: productivity and employment [6]. Thus, a study on the key factors of regional competitiveness in Europe [7] defines it as "the capability to produce goods and services that meet the market requirements, at the same time maintaining high and sustainable incomes" or, more generally, as "the capability of regions to generate relatively high incomes and employment when facing foreign competition." Similar definitions are those given by the European Commission [8]: "the ability of companies, industries, regions, nations and supra-national regions to generate, while being exposed to international competition, relatively high income and employment levels" and the European Competitiveness Report (see [6, 9]): "competitiveness is understood to mean a sustained rise in the standards of living of a nation or region and as low a level of involuntary unemployment, as possible." 
Two broad approaches of regional competitiveness were identified [7]: (i) as aggregate of companies' competitiveness, the basic assumption being that the interests of the companies and of the regions where they are located are always convergent, which is hard to support given the fact that the companies seek for productivity and profits, while regional competitiveness requires also taking into account the employment, the institutional milieu, and the market structure, and (ii) as derived from the macroeconomic competitiveness, the limits of such an approach concerning the fact that some laws that govern foreign trade do not apply at subnational level (the exchange rate dynamics and the wage-price flexibility either do not work properly or do not exist at regional level), while, conversely, the interregional migration of mobile production factors (capital and labor) may turn into a real threat for the regions [10].

However, many other studies consider as unrealistic such an approach of regional competitiveness, since the regions are neither mere aggregations of companies nor lower-scale models of national competitiveness. In this respect, some studies $[7,11]$ argue that regions compete one against each other on the basis of absolute advantage rather than on that of comparative advantage and that a region has an absolute competitive advantage when it also has technological, social, institutional, and infrastructure assets external to the companies but of which they benefit from, which confer high productivity to the respective region. Thus, at regional/subregional level, competitiveness must reflect that, besides the presence in each region/subregion of a mix of very competitive businesses/economic structures and uncompetitive others, there are certain common features within each region affecting the competitiveness of all the businesses located there, including, inter alia, the physical and social infrastructure, workforce qualification, and effectiveness of public institutions. Productivity is important not only in that it affects the comparative advantage of a region's export sectors but also in a whole range of industries and services in the region $[7,10]$. Competitiveness depends on the productivity with which a location uses its human, capital, and natural resources, setting the sustainable standard of living [12]. In this line of argument, a newer approach of the concept of national competitiveness, productivity-based, which may be used to analyze the regional level, is the one proposed by Delgado-Ketels-Porter-Stern (DKPS): the foundational competitiveness, defined as the expected output per person of working age, given the overall quality of a country/region as a location for economic activity [13]. The foundational competitiveness defines the competitiveness in terms of results based on a modified concept of labor productivity: GDP per capita considering the number of working age population, as an approximation of the potential labor force instead of the real one. In addition to productivity, another indirect result included in this approach is the maximum use of labor.

The concept of competitiveness is often perceived as the ability of a country/region to generate long-term welfare of its inhabitants. The analysis of competitiveness proposed by Aiginger (see $[14,15])$, which considers competitiveness in terms of welfare raised a new question mark: what is the measure of economic performance that the notions of competitiveness should analyze (including at territorial level)? The productivity-based approach common in literature presents the income (expressed through related indicators, such as GDP per capita) as the ultimate measure of economic performance [16, 17]. However, lately more and more criticism was raised about the fitness of monetary income for the aims of a society, in terms of environmental sustainability and the complexity of relations between this and other dimensions of 
economic and social progress. As a result, new and related approaches regarding competitiveness have emerged which include goals and indicators of post-GDP type, welfare economics, economics of happiness, etc. (see $[15,17,18]$ ).

The complexity of the regional competitiveness concept may be also revealed by different multilevel frameworks of analysis. For instance, the analytical breakdown by four levels [19], where different types of determinants act, is as follows: (i) the micro level, the determinants of competitiveness focusing on the efforts of companies and their collaboration/business networking; (ii) the meso level, which aims to create an enabling environment for businesses, the determinants focusing on the physical infrastructure, on the sectoral policies oriented toward competitiveness (education and R\&D, industry, environment, promotion of exports), and on the policies with unequivocal territorial focus (regional policy, localization policy, territorial promotion); (iii) the macro level, which includes the macroeconomic, political, and legal framework that fosters competition, the main determinants being connected to the monetary, budgetary, and fiscal policy, trade and exchange rate policy, and competition and consumer protection policy; and (iv) the meta level, which covers the basic guidelines of society, the determinants referring to the competitive economic system, the ability to develop visions and strategies, the value system that encourages learning and change, the collective memory, the social cohesion, the social capital, and the social status of entrepreneurs. In the regional/ subregional/local area, all the four levels are interconnected, even if their degree of relevance is different; but in recent years, the importance of the meta level seems to have increased in the territorial units in terms of choosing the ways and means of development, especially on the medium and long terms [10]. Also, the pyramidal model of competitiveness, based on the input-output-outcome relationships, systematizes the impact factors of the complex processes affecting welfare, labor productivity, and employment (see [6, 20, 21]), starting from the basis of success determinants (economic, environmental, and cultural processes and parameters), moving upward through competitiveness factors toward competitiveness outputs (revealed competitiveness indicators, such as gross regional product per capita, labor productivity and employment rate), and the ultimate competitiveness outcome - the standard of living, the quality of life of any region.

However, on a relatively more practical level, other definitions of regional competitiveness emerged. For instance, the definition proposed by the report on the EU Regional Competitiveness Index 2013 integrates both the companies' perspective and that of the residents of the region: "regional competitiveness can be defined as the ability to provide to businesses and residents a working and living environment attractive and sustainable," sustainability being the capa bility of a region to provide an attractive environment, both on long and on short terms [22, 23]. In this way, it responds to the discussion that gross domestic product (GDP) is insufficient by itself and should be complemented by a broader range of measures [24].

To the already complex domain of economic growth and development where competitiveness is generally discussed, the economics of sustainability and complexity has added a new component - the economic resilience, which means identifying ways and means of solving problems of increasing resistance, the ability to stop or recover the negative effects of external shocks, which lately became a fundamental feature at micro and macro level. Resilience deals 
with reducing the probability of failure or economic risks, assuming combined analytical and predictive approaches, ex post and ex ante [25], being broadly described as the ability of an economy to recover from or adjust to adverse exogenous shocks and to benefit from positive shocks [26].

Similar to the wide-arching economic concept of competitiveness, a universally accepted definition of economic resilience is not found in the literature, and there are differences of opinion among experts regarding the content, specificity, and area of coverage. Broadly, two meanings of the notion, not necessarily interfering, have been identified [25]: one based on the analysis of economic equilibrium that concerns the ability of an economic system to return to a preexisting state in a unique balance system and another one based on the theory of complex adaptive systems that refers to the ability of a system to adapt and to change in response (reaction) to sudden pressures, shocks, and negative impacts. In both meanings, two aspects (coordinates) are important: (a) the ability to return to a previous state of equilibrium (optimal) without the system changing its fundamental structure (a "takeover of valuable, valid tradition/heritage" or, as according to the evolutionary perspective, the strong rooting of resilience of regions in their past legacy, as embodied in their industrial, network, and institutional structures - see [27]) and (b) responsiveness, the system response to external or internal shocks without returning to the previous state but with recovery and stabilization in a new equilibrium (validation of Schumpeterian formula of "creative destruction" in the new conditions that support growth and technological and socioeconomic renewal in a constructive and not "demolishing" way [25] or the capacity of a region to develop new growth paths in the evolutionary approach [27]).

At local level, the phenomenon of resilience of regions/locations, as a possible response to the uncertainty and to various rapid and volatile changes in the social and economic environment, began to capture the attention of both researchers and policy makers. The issue of regional "resilience" is, basically, quite old, namely, why some regions manage to overcome short- or long-term economic adversity and maintain the standard of living of their citizens and others fail, but is not limited to regional sensitivity to economic shocks or other shocks, which induce serious economic and social problems (for instance, natural disasters - see [28]). Moreover, a region with high resilience does not only achieve short-term economic success, but it is also able to maintain it on the long term, despite (or perhaps in response to) the continuous pressures toward adaptation induced by changes in the international competition, in the consumer behavior, etc. For these reasons, it is a matter of interest regarding the political discourse and the governance capacity and successful implementation of policies and strategies at regional level.

The regional resilience as such is widely discussed in the literature, and several definitions may be identified. In principle, this is defined as the ability of a region to record economic success accompanied by social inclusion, to protect the environment, and ability to overcome (fast) the shocks [29], by reconfiguring its structure (firms, industries, technologies, and institutions - see [30]) or as the ability of a regional economy to maintain or return to a preexisting state (typically assumed to be an equilibrium state) in the presence of some type of exogenous (i.e., externally generated) shock. Thus, resilience is typically concerned with the extent to which a regional or national economy is able to return to its previous level and/or growth rate of output, employment, or 
population after experiencing an external shock [31]. Shocks may be of different kinds, such as shocks caused by downturns in the national economy, shocks caused by downturns in particular industries that constitute an important component of the region's export base (industry shocks), and other external shocks (a natural disaster, closure of a military base, movement of an important firm out of the area, etc.: see [31]). This is connected to the ability to withstand or respond adequately to external pressures (the so-called short-term resilience) and long-term adaptability (or learning ability) accompanied by the capacity of governments to engage in actions and processes for implementing appropriate policies and strategies and social learning (the so-called long-term resilience). In such a context, the concept of resilience shows that regions should have a variety of businesses, institutions, and sources of energy and food, the ability to adapt to changing environmental conditions, the ability to reorganize in the event of a shock, many small localized activities (without predominance of a particular sector), a healthy core of households, elements of civil society, and community spirit to share and collaborate to provide essential services [32]. In other words, among the determinants of adjustment and adaptation ability of a region may be mentioned the regional innovation-learning system, modern infrastructure, highly skilled workforce (innovative and willing to engage in entrepreneurial activities), and appropriate funding schemes and diversified sectoral basis $[28,33]$ - which do not differ from the success factors envisaged by regional competitiveness.

The literature reveals various types of economic resilience, based on economic performance, on how to respond to shocks (both negative and positive), and on other determinant factors [34]. An important factor is the time interval used to assess resilience, since the long-term resilience trajectory may be different, even if the end result may be similar and the (possible) path determines the optimal policy for the region [35]. For instance, Martin (see [30]) identifies four dimensions of regional resilience: resilience as resistance, recovery, structural reorientation, and renewal or resumption of a growth path. The first two roughly correspond to the concepts of engineering resilience, which focus on the resistance of a system to disturbances and the speed it takes to return to its pre-shock state, and ecological resilience, which analyzes the magnitude of shocks that can be absorbed before the system changes form, function, or position, while the two latter dimensions provide a rather evolutionary perspective. Increasing interest in the evolutionary approach to regional resilience was more recently revealed (see, for instance, $[27,28,36])$, which is focused more on the long-term evolution of regions and their ability to adapt and reconfigure their industrial, technological, and institutional structures in an evolving and dynamic economic system. In such a framework, resilience seen as the capacity of a region to sustain long-term development is regarded as important as the capacity of the same region to respond positively to short-term shocks [27]. Resilience depends on the ability of regions to cope with structural change and to create new growth paths, in order to offset inevitable processes of stagnation and decline in their regional economy, but the basic need for fundamental economic renewal is more acutely felt by regions in times of crisis. Resilience is fundamentally a dynamic process, implying the ability of a regional economy to reconfigure and adapt continuously its structure in order to maintain an acceptable growth path or the ability to create new variety or novelty in response to external shocks $[27,30]$. However, the ability of a region to permanently reinvent itself might be blocked by the regional socioeconomic conditions, and in such a context, disturbances, which are often 
reinforced by recessions, may have positive effects by releasing potential for structural adaptation [30]. Resilience trajectory is thus multidimensional (with respect to strength (resistance), recovery, reorientation, and renewal) and is directly related to the past economic performance previous to a shock [33].

More recently, interest in regional vulnerability to shocks and their trajectories to overcome and return to growth increased with the onset of the global economic crisis in 2008, a number of European studies highlighting the differences between the different regions of Europe regarding the size of recession and the subsequent economic recovery (see [33, 37-39]).

The crisis hits the EU regions during a phase of progressive regional convergence: between 2000 and 2008, the regional disparities in GDP per capita were shrinking, largely due to the positive dynamics of the regions in the NMS of the European Union, a convergence trend that came to a halt and then reverted toward divergence in 2010 and 2011 [40]. In the European Union, the issue of economic convergence among the member states and among their regions is linked with the main objective of the Union. Article 2 of the Treaty of Rome, amended by subsequent treaties, lists "a high degree of convergence of economic performance" and "economic and social cohesion" among the objectives of the European Union (EU). The Maastricht Treaty includes three economic objectives concerning convergence: the harmonious and sustainable development of economic activities, the high performance level of economic activities, and the economic and social cohesion and solidarity of the member states. The economic and social cohesion at regional level is a fundamental objective of the European Union (EU), being considered as a key driving force for the integration of people and territory. It was especially reinforced in the Treaty of the European Union, which called for balanced development, as well as economic and social cohesion, but the need for policies to promote both regional development and a reduction in the economic disparities across regions has increased remarkably after the latest waves of enlargement [41]. Delivering this objective at territorial level lies at the heart of the Europe 2020 strategy, being also a key theme of "inclusive growth" [42, 43]. In particular, the objective of regional convergence aims at reducing regional disparities by helping those regions whose income per capita is below $90 \%$ of the EU-27(28) average, but the intentions of the EU national and regional policies are not only to reduce the disparities between the levels of economic development of the various regions and the backwardness of the least favored regions but also to cap the disparities in social welfare and ultimately to improve the EU citizens' quality of life [41, 43].

The economic convergence refers usually to the process of reducing the economic, development, or socioeconomic gaps of the less-developed/emerging countries/regions/territories toward the developed countries, regions, or territories. Economic growth theories (neoclassical-exogenous growth and endogenous growth) and economic integration theories are often associated with the processes of convergence or divergence (see [44-46]). Different definitions of convergence are found in the literature, which correspond to different concepts related to convergence, two types of convergence being identified in the neoclassical growth theories: (1) absolute convergence (also known as the beta convergence), which implies that poorer countries or regions tend to grow faster per capita than the rich ones, and (2) conditional convergence (the sigma convergence), which implies that an economy grows faster the further it is from its steady-state value, 
regardless if it is poor or rich [44]. The beta convergence appears to be a necessary, but not a sufficient prerequisite for the sigma convergence, because random shocks can disrupt the convergence of countries/regions, evolving toward different stable states [47]. Though much contested (see [48]), in the literature on economic growth, the groups of economies were identified and analyzed (countries or regions) that present homogeneous economic growth patterns and that converge toward a common steady state, called the convergence clubs (see [49-52]). Finally, the integration theories with neoclassical or endogenous growth bases may argue both a tendency toward regional convergence and toward regional divergence in the EU [46].

Real convergence is a process endogenous to each national entity, and the convergence of regions within the member states is very important for improving European cohesion and the competitiveness and efficiency of the Single Market. Currently, the Europe 2020 Strategy that aims at achieving smart, sustainable, and inclusive growth stresses the need for reducing regional disparities, stating that "Regional development and investment also support inclusive growth by helping disparities among regions diminish and making sure that the benefits of growth reach all corners of the EU" [53]. Real convergence was one of the major objectives of the EU cohesion policy in the period 2007-2013, and it has covered the poorest EU regions, defined as convergence regions. The key objective in these regions, eligible for the cohesion policy, involved the stimulation of growth potential to maintain and achieve high growth rates in such regions [54]. The overall objective of the EU regarding real convergence also overlaps with and requires the territorial convergence. Sustainability of economic growth and closing the development gaps among the EU countries involve both structural reforms and, especially, a balanced contribution to the national development of regions and subregions, according to their potential, and the cohesion policy reform aims to ensure maximization of regional contribution to growth by adapting the community assistance to the development of each region and by channeling resources to the key sectors for growth.

In accordance with its significance for the national and regional development policies in the $\mathrm{EU}$ and worldwide, the regional convergence issues were highly debated in the economic literature, especially since the beginning of the 1990s, when a sharp increase in the scholarly interest has occurred in the area of regional income convergence [55]. Regional inequality has been intensively studied since the 1950s, but it has gained increasing attention more recently, mainly because of developments in the fields of economic integration, economic geography, and endogenous growth and development [56]. In literature, theories of convergence and divergence examine the reasons for diminishing or increasing the disparities between the rich and the poor regions and, in the case of divergence, explain the persistence of such disparities. As stated by Barro and Sala-i-Martin (see [57]), regional income convergence applies if a poor region tends to grow faster than a rich one, such that the poor region catches up with the rich region in terms of the level of per capita income [55]. Different definitions of convergence can be found, corresponding to different concepts related to convergence, based on economic growth theories (neoclassical growth model and endogenous growth theory) or on economic integration theories (neoclassical or endogenous growth bases - e.g., [46]). Since the 1990s, the most prominent theoretical and empirical models of regional economic growth convergence were considered to be those established by Barro and Sala-i-Martin [44, 57] and Romer [58]. 
A large body of devoted literature has suggested the presence of a polarization pattern in Europe, including two differentiated groups of regions (or convergence clubs): one of relatively poor regions and the other of regions evolving around the mean income. Moreover, such studies also revealed that such a polarization pattern has been a persistent trend especially in the Western Europe over the last three decades (e.g., [49]), making the successful implementation of policies aimed at reducing these disparities essential for achieving the targets of cohesion policies [41]. Moreover, the EU as a whole is accommodating the integration of the new member states and their regions, which at the moment of accession were economies in transition with levels of income per capita far below the EU average [10, 41]. Last but not least, to all these add up the effects of the global financial and economic crisis, which might be of interest from the convergence point of view, since the recession that has disrupted the growth mechanisms has had an uneven impact across regions, affecting countries and regions differently depending on their responsiveness and reaction [41, 59].

Instead of conclusions, we may say that by only examining the definitions and conceptual aspects regarding competitiveness, resilience, and convergence of regions, the complexity and dynamics of these domains are obvious. Though all the three topics were rooted mainly in the older and newer theories of economic growth and development, the conceptual spread, time perspective, and political focus varied, in line with the theoretical developments but also, to a great extent, in response to the impacts of exogenous shocks and/or the changes in the $\mathrm{EU}$, the national and the regional socioeconomic and political priorities and policy agendas. Considering competitiveness, resilience, and convergence of regions as specific continuous and very dynamic processes, rooted in the same economic foundations, their relationships and their relationships with other socioeconomic and policy domains reveal as increasingly complex and evolving. None of them is over-comprehensive; all of them may be examined through very different and divergent lenses (without capturing their full meaning but also without diminishing their scientific and analytical relevance), and all of them may be quantified and visualized with the help of the same (or similar) instruments (indicators, models, methods, techniques, and methodologies). Their importance may vary with the momentarily shifts in the social, economic, and political priorities of nations, regions, and unions of nations, and their acuteness may painfully surface on the occasion of man-made or nature-induced events, but they will function as long as the human societies will exist in their current forms. To know and understand them in a comprehensive fashion are a science, but to employ them to the benefit of all humans inhabiting the areas where they manifest themselves may be an art. No region, country, or the EU itself may say that it is "the most talented" at doing that, despite the temporary rankings and even the longer-time trends; all of them, as socioeconomic and political systems - the NMS and their regions included - are continuously learning, experiencing, and living the processes of competitiveness, resilience, and convergence.

\section{Assessment of regional competitiveness, resilience, and convergence}

The issues of regional economic growth and of reducing the development gaps between the EU regions have attracted attention especially after the creation of the Single European Market 
(SEM) and the European Monetary Union (EMU), but at first the empirical research focused mostly on the discussion of convergence-divergence and types thereof. Economic theories on competitiveness firstly focused largely on economic growth, stressing the importance of rise in revenues and prosperity - in accordance with the definitions of prosperity based on competitiveness. Most studies that modeled competitiveness used the Solow-Swan neoclassical model (see [60]), which operates with assumptions such as the market with perfect competition, the absence of externalities, constant efficiencies of scale, and constant and positive elasticity between inputs of capital and labor.

The most common method to describe the regional competitiveness performance is based on the decomposition of aggregate macroeconomic indicators, to identify the factors that determine economic growth, productivity, and regional development. Such a system is usually based on the decomposition of GDP per capita, which is a general measure of national, regional, and social competitiveness (see [61]) and is determined by a combination of interrelated factors, among which we first mention labor productivity and unemployment rate, but also others, reflecting different determinants of competitiveness: main sectors of the economy, competitiveness being high if the sector with high labor productivity has a high share of employment in total population, and sectors of economic activity, the effect of sector labor productivity on competitiveness being dependent on the ratio of sector employment to the total number of population and on the share of sectoral GDP to global GDP.

Measurement of competitiveness based on competitiveness indices is also frequently used in literature, but it is difficult to develop an aggregate indicator for the assessment of regional competitiveness using defined elements. The index of competitiveness is a vague concept that cannot be measured directly, and in practice the main indicators of competitiveness are interrelated, being difficult to reveal causality. However, one may distinguish between the factors that determine competitiveness and its results. Most such studies use global indices of competitiveness applied at national level (for instance, the indices developed by the World Economic Forum and the International Institute for Management Development). There are also regional competitiveness studies with fewer indicators than the national competitiveness indices, and examples of such indicators are the World Knowledge Competitiveness Index, the European Competitiveness Index (ECI), the United Kingdom Competitiveness Index (built the company Robert Huggins Associates), the Atlas of Regional Competitiveness (Eurochambres), and the World Competitiveness Index of Regions (WCIR) (see [62]). Examples of composite indices used in studies developed in the NMS to assess regional competitiveness are in Romania, the regional competitiveness index of the Applied Economics Group, regional competitiveness index proposed by IRECSON, and indices of regional competitiveness built on an integrator model [16, 63]; in the Czech Republic, the index of regional competitiveness in terms of economic performance, development of regional innovation system, and quality of life (see [64]); in Poland, the index concerning regional competitiveness in accordance with Huggin's threefactor model of regional competitiveness developed by Bronisz et al. (see [65]); etc.

In the European Union, an index of competitiveness of the regions has been developed (Regional Competitiveness Index: RCI: for the NUTS-2 regions), starting from the methodology used by the World Economic Forum, which annually publishes the Global Competitiveness 
Report of the nations of the world, including 11 pillars and 74 indicators (version 2016) organized into three groups (basic competencies, determinants of efficiency, and determinants of innovation), covering a range of factors wider than the purely economic aspects. The pillars of this indicator are basic competencies, (i1) the quality of institutions, (i2) macroeconomic stability, (i3) infrastructure, (i4) health, and (i5) quality of primary and secondary education; determinants of efficiency, (ii1) higher education and lifelong learning, (ii2) labor market efficiency, and (ii3) market size; determinants of innovation, (iii1) openness to adopting new technologies (technology awareness), (iii2) business sophistication, and (iii3) innovation. The three RCI dimensions - Basic, Efficiency, and Innovation - are linked. The i1-i5 pillars are more important for the less-developed regions while the iii1-iii3 pillars for the more advanced regions (especially for those with a very high development level) but also for the regions in transition from a lower to a higher development level. A region with a good performance in the innovation group is expected to have a good performance in the Basic and Efficiency groups as they are instrumental in increasing levels of competitiveness. In this sense, Basic and Efficiency aspects may be considered as necessary conditions for good levels in Innovation aspects. Conversely, regions with poor or insufficient levels in the Basic group cannot be expected to perform well in the other two groups. It is assumed that as regions move along the development path, their socioeconomic conditions change, and different determinants become more and more important for competitiveness. As a result, improving the competitiveness of more developed regions will require other priorities than for a less-developed region [23, 24]. This is reflected by a weighting system that takes into account the stage of development. In the 2013 and 2016 editions of the RCI, the EU regions were divided into five development stages based on their average GDP per head in purchasing power standard (PPS) expressed as an index (EU-28 $=100)$. In more than $70 \%$ of the cases, the development stage remained unchanged from one period to the other, while about $8 \%$ of the regions improved their development stage (from one class to the one immediately above it, regions from Austria, the Czech Republic, Germany, Poland, Romania and Slovakia - see [24]).

The RCI results of 2013 and 2016 showed a remarkable diversity of regional competitiveness in the European Union, both among the member states and within them. Some significant differences between the group of "old" member states (EU-15) and the "new" member states (NMS-13) were noticed, both in terms of the RCI and territorial distribution of factors of competitiveness and channels to disseminate it among the regions. The top ten competitive regions of the European Union belonged all to countries of the EU-15 (United Kingdom four regions and the Netherlands, Sweden, Germany, France, Luxembourg, and Denmark one region each version 2016). In contrast, the last ten regions in the top of competitiveness are almost equally located in the EU-15 member states (Greece five regions and France one region) and NMS-13 (Romania three regions and Bulgaria one region). Although the changes in a region's ranking over time may not be always meaningful, because the rankings are based solely on the sequence of the scores (the ordinal properties) and do not take into account the actual differences between scores [24], one may notice that in most of the EU countries (Austria, Bulgaria, Czech Republic, Denmark, Spain, Finland, Hungary, Poland, Portugal, Romania, Sweden, and Slovakia), the regional scores were quite stable from 2010 to 2016. 
Assessment of regional competitiveness based on multilevel systems of indicators is also commonly found in literature: for instance, the abovementioned pyramidal model of competitiveness [6], which builds upon both endogenous growth and development theories. Assessment of competitiveness of the NUTS-2 level regions of eight Central and East European countries (Austria, the Czech Republic, Germany, Hungary, Poland, Romania, Slovakia, and Slovenia) revealed that the socioeconomic-historical background and past impact still subsist (a conclusion resembling some of the elements of the evolutionary approach of resilience) and the characteristics, institutional background, etc., of a given country still determine the regional characteristics, the differences between countries being stronger than the differences within the analyzed countries (see [6]).

In another perspective, other approaches to assess regional competitiveness are used, such as panel data models and DEA to measure the regional effectiveness; multivariate statistical methods, such as the cluster analysis method; the principal components; and the factor analysis to measure competitiveness factors [66]. More recently, panel techniques were employed to assess regional competitiveness and analyze its factors of influence, due to their advantages over the traditional approach using linear regression and the possibility to use data from different economic levels (micro, meso-, and macroeconomic). For instance, the panel model to assess regional competitiveness in the EU-15 was built by Lukáš and Jan (see [1, 67]), in which regional productivity and competitiveness were analyzed in relation to the theories of economic growth. A nonlinear panel model was estimated for 35 NUTS-2 regions of the EU-15 over the period 2000-2008, and the global competitiveness in the EU was approximated using the average GDP per capita in PPS. The explanatory variables were R\&D expenditure, net disposable income, and gross capital formation. An econometric model on panel data was used by Nevima and Melecký [68] to measure the level of regional competitiveness for the Visegrad four countries, in terms of performance indicators that appear in the strategies of economic growth in the European Union until 2010. The explanatory variables were chosen to reflect the competitive potential of the NUTS-2 regions of the Visegrad countries. Among these regions, significant acquisitions of production were noticed in the regions of Prague, Bratislava, Nyugat-Dunántúl, and Közép-Magyarország. Three regions of Poland were found to be the least productive: Lubelskie, Malopolskie, and Łódzkie. For Romania, regional competitiveness was assessed by Iordan et al. (see [69]) based on a dynamic panel for 42 counties in Romania, including Bucharest, between 2000 and 2012. The authors showed that the current GDP depends on the number of employees and the GDP of the previous period. Researches on economic development and competitiveness of the regions of Romania analyzed in terms of GDP per capita and determinants thereof [16, 70,71] have suggested a wide gap between regions, with rising trend, revealing three potential "performance levels": "engine regions" (Bucharest-Ilfov), "follower regions," and "lagging regions." Pelinescu et al. (see [1]) examined the extent to which the Romanian regions generate sustainable revenues, expressed by the GDP growth, and create jobs, finding among the counties of Romania a significant positive correlation between the rate of real GDP and the employment rate, a region/county being the more competitive as it had a higher degree of employment. Analyses undoubtedly showed the need to raise employment at county level in Romania, because it has concentrated mainly in the [54 and 64\%] range, far from the 70\% level foreseen in the Europe 2020 Strategy. 
As regards measuring the regional economic resilience, two approaches are commonly used (see [72]): one that examines regional properties or characteristics that reflect economic resilience, such as macroeconomic stability, microeconomic market efficiency, governance, and social development [73]; the degree to which resources are owned locally, the organizational capacity of residents, and the local capacity of institutions to adapt and reorganize in response to a shock; local knowledge network structure; income equality, economic diversification, regional affordability, and business environment [74], and another that analyzes changes to a region's representative measure in response to a shock, by using, for instance, correlations between unemployment and gross domestic product (GDP), population, share of manufacturing, construction, finance, and public infrastructure investment [72, 75]; structural composition of employment change across industries; regional employment change rates during recessionary and recovery periods [30]; and employment and employees' dynamics during different periods [76].

The empirical attempts to measure regional resilience usually look at changes in regional indicators, like the unemployment rate, employment or income level, to assess the impact of an external shock on a regional economy's growth path or the time it needs to recover. From an empirical perspective, the regions differ in their resilience usually in terms of regional growth or (un)employment [38]. Some authors analyzed other determinants of regional resilience, such as firms' growth rate (see $[77,78]$ ) or the degree and nature of regional urbanization, directly and indirectly linked to regional growth [38]. The composition and the size of the population of a region are considered among the most important determinants of regional growth, and the regions that have a more skilled population or work force do perform better, while, by and large, the regions that are more urbanized also outperform less urbanized regions. The possible relevance of the degree and composition of urbanization for resilience is to be found in the fact that urbanization also signals the degree to which cities or regions are able to adjust to shocks [79]. Findings on 255 EU NUTS-2 show that the EU regions with a relative large share of their population in commuting areas are relatively resilient, while, in contrast, the regions with a large share of people living in rural areas or small cities face more difficulties in absorbing shocks [38].

As mentioned above, the resilience of regions in relation to the impact of the 2008 economic crisis became more recently of high interest to the economic specialists and practitioners [80, 81], and the studies found, in general, several categories of resilient regions among the EU regions [39]: resistant (not adversely affected by the economic crisis $-12 \%$ of the NUTS-2 regions, $16 \%$ of the NUTS-3 regions), recovering (adversely affected by the economic crisis but have recovered to former peak - $23 \%$ of the NUTS- 2 regions, $24 \%$ of the NUTS-3 regions), revealing upturn (adversely affected by the economic crisis but experiencing upturn and yet not recovered to their former peak $-33 \%$ of the NUTS- 2 regions, $28 \%$ of the NUTS-3 regions), and revealing no upturn (adversely affected by the economic crisis and not yet experiencing upturn $-33 \%$ of the NUTS-2 regions, 33\% of the NUTS-3 regions). In the particular case of Romania, such studies showed a greater resilience of Bucharest-Ilfov region's economy and continuing fragility of many other regional economies and the difficulties associated with structural changes and integration into the EU economy (see, for instance, [37, 39, 75, 76]). Other studies found a complex core-periphery pattern [40], with a "core" continental area, 
where the impacts of the 2008 crisis were low or moderately low, including Germany, most of Poland, and partly stretching to the neighboring regions (most regions of Slovakia and the Czech Republic), surrounded by a ring of more peripheral areas where the impacts were high/very high (including most of the regions of Ireland, Spain, parts of Italy, Greece, Cyprus, Lithuania, Latvia, and Estonia).

The link between pre-crisis national and regional resistance factors and the short-term regional economic consequences of the recession was the topic of interest for other studies (see [40]), the empirical results suggesting that while the pre-crisis regional development trajectories were highly heterogeneous both in terms of economic growth and employment dynamics, after the crisis a marked center-periphery spatial pattern has emerged. The within-country regional imbalances have shrunk in most of the EU countries, but the regional disparities across the EU as a whole have increased both in terms of gross domestic product (GDP) and unemployment [40]. While some regions of the NMS showed even positive performance during the crisis (the Polish regions in terms of GDP), others were more seriously hit (for instance, regions in Croatia, Slovenia, Cyprus, and Bulgaria in terms of unemployment). Worth noticing is the fact that among the many quantitative features of regional economies that shape their ability to resist and adapt to shocks and change, mostly relevant to the regional resistance were found to be the regional industrial mix and a group of regional competitiveness/ innovation factors (human capital and skills and innovation efforts [40, 82]).

Finally, the process of real convergence of the EU member states and their regions has been extensively studied, either in a macroeconomic context and considering its relationship with the nominal convergence or in connection with the concept of cohesion (economic, social, and territorial: see, for instance, [42, 46, 83-86]). The main indicators used to analyze real convergence refer to the differences in GDP per capita at purchasing power parity and in income per capita, differences in labor productivity, and the price level (e.g., [87-90]). The literature highlights several indicators that can be used to assess the real convergence process, from broader indicators (GDP growth rate, GDP per capita, the ratio of exports to GDP, the intensity of foreign investment, stock market capitalization, unemployment rates, labor costs and R\&D expenditures, etc.) to specific indicators and modeling methods used to assess the beta and sigma convergence, the convergence clubs, and the concentration and entropy of the process (coefficient of variation, Lorenz curve, Gini index, Atkinson index, Theil index, average logarithmic deviation, Robin Hood index, Markov chains, panel regressions, nonparametric methods, etc.: see $[47,88,90-94])$.

The results of existing empirical studies on the EU provide mixed evidence. Some studies have generally revealed the presence of absolute convergence between the EU member states and their regions, but the pattern and speed of convergence were found to vary sharply across different subperiods and regional subsets (including periods of divergence), with peculiarities for the EU-15 countries and the new member states and also within these groups of countries (see [54, 95-100]). Iordan and Chilian (see [101]) have also found mixed evidence regarding the real convergence in the EU regions, with both peculiarities and similarities for the regions of the EU-15 and NMS13 countries. Both a single highly developed region, usually the region where the capital of the country is located, that has registered the best performance in terms 
of real convergence, and the presence of several well-performing "regional growth engines" (in Italy, the Netherlands, Spain, and Finland but in none of the NMS13) were noticed. Also, in the case of the most developed regions from the EU-15 countries (but also in some NMS13 countries), the very high level of GDP per capita and its growth trend up and away from the EU average make the "weak" performance in terms of real convergence as usually defined in literature (as catching-up toward the average) a logical consequence. This might call for a redefinition of the real convergence as, for instance, catching-up not toward the average, but toward the highest regional GDP per capita level, which may dramatically expand the growth gaps and redraw the map of convergence/diverge clubs identified so far among the EU regions [101].

Especially important was the uneven impact of the crisis upon particular countries when examining convergence, with the convergence tendencies of the NMS continuing even after the crisis years of 2008 and 2009 while the periphery countries of the EU-15 diverging remarkably in that period [102]. Also, a more detailed study of convergence of the regions of the EMU countries revealed that even in a currency union, the convergence of regions to the country mean was far from automatic, highly discontinuous, and strongly concentrated on a rather limited number of time periods. Only around half of the regions starting with below national average GDP per capita levels in 1991 experienced a catch-up over the period 1991 to 2009, and only two thirds of the regions starting with above national average GDP per capita in 1991 converged toward the respective country average until 2009 [103]. At the same time, across the EU the conditional convergence was less pronounced, signaling increasing disparities among the regions [46, 95], especially in the EU-15 countries but also in the NMS, revealing the existence of selective tendencies, convergence clubs, and asymmetric shocks, which might lead to greater spatial inequalities (see [104, 105]). Moreover, the European Commission's successive Periodic Reports show that real economic convergence is a long way off and in some countries regional economic disparities have even worsened [106-109]. In the particular case of Romania, different studies assessed the growth process at regional and subregional (county) levels, especially in connection with the process of GDP convergence toward the EU national and regional average levels (see, for instance, $[89,110,111]$ ). The intra-regional gaps in terms of GDP per capita in Romania revealed an increase in the territorial concentration of economic growth, especially during the post-accession period, including in the more developed regions (Nord-Vest, Centru, and Vest), and significant oscillations during the period of crisis [111]. Such findings suggest that similar to the more developed regions [74], also the more developed counties have benefitted most from the EU accession and were more able to absorb the shock of economic crisis and to return to a path of economic growth, signaling greater resilience and adaptability. However, such developments are not specific only to Romania, but they are also found in other newer or older EU member states (see [10, 112, 113]).

A concept associated to real convergence is the structural convergence/convergence of economic structures, developed by Wacziarg, who established that structural convergence occurs if convergence in per capita income is accompanied by sectoral convergence. In order to study the structural convergence/specialization, different dedicated indices may be used, such as the Krugman specialization index, the location quotient, structural coefficients, and other disproportionality measures [114-116]. Different trends in the European industries were revealed by 
empirical studies, such as the increase in regional industrial concentration of both declining traditional industries and the growing advanced sectors or the increase in regional specialization in manufacturing. Some findings regarding the NMS revealed a split performance between the capital regions and the regions bordering the EU, which managed to combine a set of positive, structural, and geographical initial conditions with market dynamics, and the other regions, which witnessed the collapse of large parts of their industrial bases, drastically cutting local demand and setting real restrictions to efforts and policies of indigenous growth [117]. Also, in the NMS the patterns of structural change in terms of both output and employment looked very much differentiated, both across time and individual European countries. In general, the structural changes were more pronounced with regard to employment than output (implying large shifts in productivity performance), with broad shifts from agriculture and industry toward services. Romania was one of the NMS that experienced significant structural changes [118]. We may find studies addressing nationally and regionally the relationship between the real and structural convergence, through indexes of real convergence and of structural convergence/divergence and their combination, which reveal a relative alignment of sector similarity and convergence in terms of per capita income (see, for instance [59, 74, 88, 113]).

The evidence is also mixed regarding the relationship of convergence in income per capita and the social convergence. Some studies (see [87]) suggested the presence of a conditional convergence in income per capita and that of an unconditional convergence in income inequality in many regions of the EU, while other studies indicated that the weak or even the lack of economic convergence is not matched by a similar absence of social convergence, as the welfare levels have converged significantly across European regions, although the regions with high social welfare levels may remain advantaged in welfare terms, while the low social welfare regions may continue to lag behind [109].

\section{Competitiveness, resilience, and convergence in the new member states}

The complexity and peculiarities of the processes of regional competitiveness, resilience, and convergence raise particular problems in terms of assessment. Two of the main questions to be answered by the scientific approach regarding their assessment are as follows: (1) How can they be adequately measured? and (2) How can we enhance and best employ their territorial specific features in such a way to ultimately raise the socioeconomic development and the standard of living of any region? The answers to these questions lead to the construction of various systems of indicators and models to assess and/or model such processes and their interconnections and the relationships with other socioeconomic processes at work at macroeconomic, territorial, sectoral, microeconomic, and even international levels.

As previously mentioned, the study presents an analysis of competitiveness, resilience, and (real) convergence in the NUTS-1 and NUTS-2 regions of the European Union NMS, based on a joint (but not composite) framework of analysis, in which the three abovementioned processes are considered together, for the moment as a loose reunion of compounds and analyzed in 
the sense of process outputs, though for space limitation reasons their relationships and the relationships with the socioeconomic spaces of whom they are components of and in which they are functioning are not fully and deeper investigated. A minimum of specific indicators was chosen from among the most used indicators in such assessments, covering a longer time span (2000-2013/2015, depending on the available data for each indicator), which includes the ante-crisis (2000-2007), crisis (2008-2010), and post-crisis (2011-2013/2015) periods. A common, "root" indicator for all the three "sides" of the framework was first chosen for analysis, namely, the GDP per capita at purchasing power standard (PPP), expressed in relation to the EU average. However, not the absolute levels were chosen, but the gross modifications over each of the abovementioned subperiods, in the sense of gross speeds of change, computed as the ratio of the difference between the absolute levels of the indicator at the beginning and the end of period to the length in years of the analyzed period (see [119]).

Other specific indicators were used to depict each of the three sides of the framework, namely:

- A productivity indicator (gross value added per employment over 15 years of age: denoted by GVAE), for the competitiveness side and in order to account for foundational competitiveness, too. This indicator was also computed in relation to the EU-28 average and as "gross modification."

- The RCI rankings of the NMS regions for 2010, 2013, and 2016, also for the competitiveness side and to account for aggregate competitiveness and its factors.

- Employment rates (denoted by EMPR), for the resilience side and to account for the regions' response to the economic crisis but also to other shocks, computed in relation to the EU-28 average and as "gross modification."

- Employment levels (denoted by EMP), expressed in thousand persons, also for the resilience side, computed as "gross modification" over the analyzed periods, in order to reveal the depth of regional adaptation.

- An income convergence indicator (compensation of employees estimated at PPP: denoted by CPSE), for the convergence side, to account for the developments in the ultimate outcome of convergence - the rise in the living standard of a region's inhabitants. The indicator was also computed in relation to the EU-27 average (excluding Cyprus) and as "gross modification."

The results reveal the following aspects (data available upon request):

Mixed evidence regarding the evolution of competitiveness, resilience, and convergence in the NMS regions was found, with both differences and similarities within and across periods, within and across countries. Thus, in most of the NMS countries, a single highly developed region, usually the capital region of the country, registered the best performance in terms of all the three processes over the ante-crisis period, except for the employment rates in the Czech Republic, Hungary, and Romania, pointing toward possible reminiscences of past adjustment shocks determined by the transition to the market economy and by inherited but yet unsolved labor market rigidities. This is more obvious especially in the case of Romania, where the ante-crisis economic growth was accompanied in all the regions except for Bucharest-Ilfov not by overall job creation, but by continuation of labor force downsizing, "delayed" from 
the transition period. Three capital regions (in the Czech Republic, Slovenia, and Slovakia) have already reached GDP per capita levels above the EU average since the ante-crisis period, accompanied by high growth rates. Besides the resilience side, the income convergence has also showed high within-country variability and even decline before the economic crisis in regions of Bulgaria, Poland, and Slovenia, more or less developed. However, the most notable was the positive performance in terms of productivity in virtually all the regions of the NMS - evidence pointing toward real advance in the catching-up process of all the countries.

Some of the "national growth engines" did not fare the same well during the crisis period, especially in terms of productivity, but revealed capability to adjust to the shock of crisis and retain and even create employment (in the Czech Republic and Romania). Different adjustments to crisis and growth paths were revealed within and across the NMS: small advances in productivity and convergence accompanied by layoffs and decline in employment rates in Bulgaria and Slovakia, some declines in productivity but still good performance in convergence, accompanied by smaller job losses and declines in employment rates in most of the regions of Poland and declines in productivity, convergence, and employment, however, accompanied by small gains in terms of employment rate evolution in most of the regions of the Czech Republic, Hungary, Romania, and Slovenia and in the smaller NMS, except for Malta. The crisis struck hard all the NMS regions, and the ones that performed poorly during the crisis were mostly the regions (and countries) with trailing and unsolved development issues.

The post-crisis period insofar revealed another mix of recovery and/or growth paths, but the overall trend looks positive, even for some of the regions that previously recorded only poor performance regarding all the analyzed processes. Except for Poland and Romania, the productivity side seems still affected by the negative impacts of the crisis, while income convergence is again mostly on an ascending path. Even more variation is noticed in the regional employment levels and employment rates, most of the NMS regions seeming to recover the lost jobs by creating others, others still experiencing greater labor force restructuring. It is worth noticing that more capital regions registered GDP per capita and even productivity and employment rate levels exceeding the EU averages (in the Czech Republic, Hungary, Poland, Romania, Slovenia, and Slovakia). As previous studies revealed, the core-periphery patterns of development were accentuated by the crisis also in the NMS, setting on a different (less balanced) footing the catching-up processes within the countries and not only across countries and regions.

However, in the case of the most developed regions of the NMS, we must again mention their very high level of GDP per capita and its growth trend up and away from the EU average, which requires a different scale to assess their performance in terms of competitiveness, resilience, and convergence, probably as catching-up not toward the European average, but toward the highest regional GDP per capita and other indicator levels. This will expand the within-countries growth gaps and will redraw the development maps and patterns identified so far also among the NMS regions, but this calls for another analysis. Redefining competitiveness, resilience, and convergence performance in terms of catching-up toward the (evermoving) absolute levels of regional GDP per capita and other relevant indicators (distance to a specific or composite development frontier) may bring new insights about how much and for how long have in fact impacted the global crisis such processes. 


\section{Concluding remarks}

The issues of competitiveness, resilience, and convergence among the European regions have generated large academic debates over the past decades, with particular interest after the recent EU enlargements. This study attempted to analyze the topics of competitiveness, resilience, and cohesion not individually, but together, in a reunion of compounds, not at national, but at regional level, based on their common roots within the economic growth and development theories, with the view to outline an integrated framework of analysis, with a direct focus on the regions of the new member states of the European Union. The study contributes to literature in several different aspects. First, it has analyzed a longer time span, namely, 2000-2013/2015, by focusing on three different subperiods delineated by the global economic crisis that started in 2008: ante-crisis, crisis, and post-crisis. Second, considering competitiveness, resilience, and convergence of regions as specific continuous and very dynamic processes, but none of them over-comprehensive, they may be examined through different and divergent lenses and may be quantified and visualized with the help of the same (or similar) instruments (indicators, models, methods, techniques, and methodologies). Their importance was revealed as varying with the momentarily shifts in the social, economic, and political priorities of nations, regions, and unions of nations, but they will function as long as the human societies will exist in their current forms. Third, besides the joint framework of analysis of the three processes, a common, "root" indicator for all the three "sides" of the framework was first chosen for analysis (the GDP per capita at purchasing power standard), accompanied by a minimal set of indicators relevant mainly for each process, but also for the others, depending on the perspective of analysis. Future fields of research (not pursued here due to space limitations) would be to analyze the relationships between the three processes within the chosen framework and their relationships with other socioeconomic processes at work in specific territorial locations and to develop a tree-like, networked system of indicators pertaining to the revealed relationships.

Though the chosen indicators were simple, but powerful, the results suggest mixed and complex evidence, with both differences and similarities within the NMS countries and across regions and countries. The "history" of past transition shocks was still influencing the recent development and integration paths of the NMS within the European Union, their adaptation processes having to deal with additional socioeconomic rigidities and burdens in an already difficult socioeconomic context. Though the crisis has impacted each country differently, in direct relation to the state of its economic structures and institutions, the post-crisis accentuation of the core-periphery pattern noticed in the "older" member states of the EU was also revealed in the NMS, where the performance of their "national engines" (usually their capital regions) went out of their specific development charts. Such evolutions might even call for redefinition of competitiveness, resilience, and convergence performance in terms of catching-up toward an (ever-moving) absolute levels of regional GDP per capita and other relevant indicators (distance to a specific or composite development frontier), which may bring new insights about the length and depth of crisis impacts on such processes and its subsequent foundational changes and would redraw the current development maps and patterns of the NMS and EU regions. 


\section{Author details}

Marioara Iordan and Mihaela-Nona Chilian*

*Address all correspondence to: mihaelanona.chilian@gmail.com

Institute for Economic Forecasting, Bucharest, Romania

\section{References}

[1] Pelinescu E, Iordan M, Chilian MN, Simionescu M. Competitivitate-Competitivitate Regionala in Romania. Bucuresti, Romania: Editura Universitara; 2015

[2] Porter M. The Competitive Advantage of Nations. New York: Free Press; 1990

[3] Martin R, Tyler P. Competitiveness, Productivity and Economic Growth across the European Regions. UK: University of Cambridge; May 2004

[4] Martin R. Thinking About Regional Competitiveness: Critical issues, Report Commissioned by the East Midlands Regional Development Agency. Nottingham, UK: East Midlands Regional Development Agency; 2005. p. 2005

[5] Lambregts B, Janssen-Jansen L, Haran N. Effective governance for competitive regions in Europe: the difficult case of Randstad. Geographic Journal. 2008;72:45-57, Springer-Verlag

[6] Lengyel I, Rechnitzer J. The competitiveness of regions in the Central European transition countries. The Macrotheme Review. 2013, Summer;2(4):106-121

[7] Martin RL, (coord.), A Study on the Factors of Regional Competitiveness. 2003, A draft final report for the European Commission, University of Cambridge, UK: Directorate General Regional Policy, Cambridge Econometrics

[8] European Commission. Sixth Periodic Report on the Social and Economic Situation and Development of Regions in the European Union. Luxembourg: European Commission; 1999

[9] European Competitiveness Report 2008, Directorate-General for Enterprise and Industry, European Commission, 27 February 2009, DOI:10.2769/65417

[10] Chilian MN. Coeziunea economico-socială la nivel regional - Elemente de fundamentare a unei strategii regionale. Bucharest, Romania: Expert Publishing House; 2013

[11] Camagni R. On the concept of territorial competitiveness: Sound or misleading? Paper presented at the ERSA Conference, Dortmund August, 2002

[12] Porter M. Clusters and Economic Policy: Aligning Public Policy with the New Economics of Competition, ISC White Paper November 2007 Rev. 10/27/09

[13] Delgado M, Ketels C, Porter ME, Stern S. The Determinants of National Competitiveness, NBER Working Paper, 2012, No. 18249 
[14] Aiginger K. Competitiveness: From a dangerous obsession to a welfare creating ability with positive externalities. Journal of Industrial Competitiveness and Trade. 2006;6:161177. DOI: 10.1007/s10842-006-9475-6 Springer Science - Business Media, LLC

[15] Aiginger K, Barenthaler-Sieber S, Vogel J. Competitiveness under New Perspectives, WWW for Europe Project, Work Package 301, Working paper, No. 44 October, 2013,

[16] Chilian MN. Competitivitatea economiei românesti si integrarea în Uniunea Europeană. Bucuresti: Editura Universitară; 2011

[17] Wilson J. Territorial Competitiveness and Development Policy Orkestra Working Paper Series in Territorial Competitiveness, Number 02. Orkestra-Basque Institute of Competitiveness; 2008

[18] Stiglitz JE, Sen A, Fitoussi JP. Report by the Commission on the Measurement of Economic Performance and Social Progress. Paris; 2009

[19] Annoni P, Kozovska K. EU Regional Competitiveness Index 2010, Joint Research Centre and DG Regional Policy, 2010. Annoni, Kozovska; 2010

[20] Lengyel I, Lukovics M. An attempt for the measurement of regional competitiveness in Hungary. In: $46^{\text {th }}$ Congress of the European Regional Science Association, Volos, Greece. August 30-September 3, 2006

[21] Gardiner A, Martin R, Tyler P. Competitiveness, Productivity and Economic Growth across the European Regions, University of Cambridge. UK; May 2004

[22] Dijkstra L, Annoni P, Kozovska K. A New European Regional Competitiveness Index: Theory, Methods and Findings, DG Regional Policy Working Papers WP02, 2011

[23] Annoni P, Dijkstra L. EU Regional Competitiveness Index 2013, JRC Scientific and Policy Reports, European Commission, DG for Regional and Urban Policy, 2013, 2013 ISBN-978-92-79-32370-6

[24] Annoni P, Dijkstra L, Gargano N. The EU Regional Competitiveness Index 2016, JRC Scientific and Policy Reports, European Commission, DG for Regional and Urban Policy, WP 02, 2017

[25] Zaman G. Reziliența economică la criză. Bucharest: IEN; 2014, manuscript

[26] Briguglio L, Cordina G, Farrugia N, Vella S. Economic vulnerability and resilience: Concepts and measurements. Oxford Development Studies. 2009;37:229-247

[27] Boschma R. Towards an Evolutionary Perspective on Regional Resilience, CIRCLE, Lund University and Department of Economic Geography. Urban and Regional research Centre Utrecht, Utrecht University; 2014 Paper no. 14

[28] Christopherson S, Michie J, Tyler P. Regional resilience: Theoretical and empirical perspectives. Cambridge Journal of Regions, Economy and Society. 2010;3:3-10

[29] Bristow G. Resilient regions: Re-'place'ing regional competitiveness. Cambridge Journal of Regions, Economy and Society. 2010;3:153-167 
[30] Martin R. Regional Economic Resilience. Hysteresis and Recessionary Shocks, Journal of Economic Geography. 2012;12:1-32

[31] Hill E, St. Clair T, Wial H, Wolman H, Atkins P, Blumenthal P, Ficenec S, Friedhoff A. In: Pindus N, Weir M, Wial H, Wolman H, editors. Economic Shocks and Regional Economic Resilience, in Building Resilient Regions: Urban and Regional Policy and Its Effects. Vol. 4. Washington: Brookings Institution Press; 2012

[32] Psycharis $Y$, Artelaris P, Kallioras D, Pantazis P, Tsiapa M. The Spatial Footprint of the Ongoing Economic Crisis (2009-...) in Greece: Assessing the Resilience and Development of the Greek Regions, ERSA Conference Papers. Bratislava; 2012

[33] Martin R. Regional Economic Resilience, Hysteresis and Recessionary Shocks, Papers in Evolutionary Economic Geography No. 10.18. Utrecht University, Urban\&Regional Research Centre Utrecht; November 2010

[34] Pike A, Dawley S, Tomaney J. Resilience, adaptation and adaptability. Cambridge Journal of Regions, Economy and Society. 2010;3:59-70

[35] Régibeau P, Rockett K. Economic Analysis of Resilience: A Framework for Local Policy Response Based on New Case Studies, MPRA Paper No. 38549 April 2012

[36] Simmie J, Martin R. The economic resilience of regions: Towards an evolutionary approach. Cambridge Journal of Regions, Economy and Society. 2010;3:27-43

[37] Groot SPT, Mohlmann JL, Garretsen JH, de Groot HLF. The crisis sensitivity of European countries and regions: Stylized facts and spatial heterogeneity, Cambridge Journal of Regions, Economy and Society. 2011;4:437-456

[38] Brakman S, Garretsen H, van Marrewijk C. The Crisis and Regional Resilience in Europe: On the Importance of Urbanization and Specialization, CESIFO Working Paper No. 4724, 2014

[39] Bristow G. Agency, choice and agenda: Developing perspectives on economic resilience. In: Resilience in Urban and Regional Development DLGS International Conference, Berlin. March 27-28, 2014

[40] Crescenzi R, Luca D, Milio S. The geography of the economic crisis in Europe: National macroeconomic conditions, regional structural factors and short-term economic performance. Cambridge Journal of Regions, Economy and Society. 2016;9:13-32

[41] Peiro-Palomino J. European regional convergence revisited: The role of intangible assets. Annals of Regional Science. 2016;57:165-194

[42] European Commission, DG Regional - Social Mobility and Intra-regional Income Distribution Across EU Countries, No. 2008CE160AT054/2008CE16CAT017, Final Report, July 2010

[43] Rodriguez-Pose A, Tselios V. Inequalities in income and education and regional economic growth in Western Europe. The Annals of Regional Science. 2010;44:349-375 
[44] Barro R, Sala-i-Martin X. Convergence. Journal of Political Economy. 1992;100:223-251

[45] Capello R. Regional Economics, Routledge. London and New: York; 2007

[46] Quineti A, Matejkova E, Pietrikova M, Serences R, Toth M, Dvorak M. Looking for the evidence of socio-economic convergence within the European Union. Agricultural Economy - Czech. 2011;57(8):384-393

[47] Neagu O. Measurement of Territorial Convergence. An Analysis in the Case of Romania, Annals of the "Constantin Brâncuşi" University of Târgu Jiu, Economy Series, Issue 32013. p. 117-125

[48] Ertur C, Le Gallo J, Baumont C. The European regional convergence process, 1980-1995: Do spatial regimes and spatial dependence matter? International Regional Science Review. January 2006;29(1):3-34

[49] Quah DT. Regional convergence clusters across Europe. European Economic Review. 1996;40:951-958

[50] López-Bazo E, Vayá E, Mora T, Suriñach J. Regional dynamics and convergence in the European Union. Annals of Regional Science. 1999;33(3):343-370

[51] Le Gallo J, Ertur C, Baumont C. A spatial econometric analysis of convergence across European regions, 1980-1995, pp: 99-129, In: European regional growth, Springer-Verlag, Berlin Heidelberg, Germany; 2003

[52] Mora T. Factors conditioning the formation of European regional convergence clubs. Annals of Regional Science. 2008;42:911-927

[53] European Commission, Inclusive growth: A high-employment economy delivering economic, social and territorial cohesion. Europe 2020, 2012, [Online], Available from: http://ec.europa.eu/europe2020/europe-2020-in-a-nutshell/priorities/inclusive-growth/ index_en.htm

[54] Jozwik B, Ponikowski H. Real convergence, economic crises and EU cohesion policy. In: Cambridge Conferences Business \& Economics, Cambridge, UK. July 1-2, 2014

[55] Lim U. Regional income club convergence in US BEA economic areas: A spatial switching regression approach. Annals of Regional Science. 2016;56:273-294

[56] Artelaris P, Petrakos G. Intraregional spatial inequalities and regional income level in the European Union: Beyond the inverted-U hypothesis. International Regional Science Review. 2016;39(3):291-317

[57] Barro RJ, Sala-i-Martin X. Convergence across States and Regions. Brookings Papers on Economic Activity. 1991;1:107-182

[58] Romer P. Increasing returns and long-run growth. Journal of Political Economy. 1986;94:1002-1037

[59] Iordan M, Chilian MN. Dynamics of real and structural convergence at sub-regional level in Romania, Proceedings of the 3rd International Conference 'Economic Scientific 
Research - Theoretical, Empirical and Practical Approaches', ESPERA 2015. Bucharest: Romania, Peter Lang Publishing House; December 3-4, 2015,

[60] Solow RM. A contribution to the theory of economic growth. Quarterly Journal of Economics. 1956;70:65-94

[61] Grilo I, Koopman GJ. Productivity and microeconomic reforms: Strengthening EU competitiveness. Journal of Industrial Competitiveness and Trade. 2006;6:67-84. DOI: 10.1007/s10842-006-9472-9, Springer Science - Business Media

[62] Huggins R, Izushi H, Prokop D, Thompson P. Regional competitiveness, economic growth and stages of development. Zbornik radova Ekonomskog fakulteta u Rijeci. 2014;32(2):255-283

[63] Mereuță C, Albu LL, Iordan M, Chilian MN. A model to evaluate the regional competitiveness of the EU regions. Romanian Journal of Economic Forecasting. 2007;3:81-102

[64] Martinãík D, Iehoferová M. Competitiveness and convergence of Czech regions: Persistence of discrepancies. E+M, Ekonomie a Management. 2014;XVII(2):14-33

[65] Bronisz U, Heijman W, Miszczuk A. Regional competitiveness in Poland: Creating an index. Jahrbuch f "ur Regionalwissenschaft. 2008;28:133-143

[66] Melecký L. Assessment of EU competitiveness factors by multivariate methods. World Academy of Science, Engineering and Technology. 2013;7:6-22

[67] Lukáš M, Jan M. Application of econometric panel data model for regional competitiveness evaluation of selected EU 15 countries. Journal of Competitiveness. 2011;4:23-38

[68] Nevima J, Melecký L. Regional competitiveness evaluation of Visegrad Four countries through econometric panel data model. Liberec Economic Forum. 2011;10(1):348-361

[69] Iordan M, Chilian MN, Simionescu M. Determinants of regional competitiveness in Romania- a panel data analysis. In: International Conference "Knowledge Economy Challenges of the 21st Century", Constantin Brancoveanu University, Piteşti, Romania. November 6-7, 2014

[70] Vincze M. Regional Competitiveness in Romania. Cluj Napoca: Babeş-Bolyai University, Faculty of Economic Sciences; 2003

[71] Chilian MN, Iordan M. Regional Competitiveness in the EU Countries. Focus on The New Member States, Romanian Economic Review. INCE, CIDE, Bucharest, Romania; 2008

[72] Han Y, Goetz SJ. The economic resilience of U.S. counties during the great recession. The Review of Regional Studies. 2015;45:131-149

[73] Briguglio L, Cordina G, Bugeja S, Farrugia N, Conceptualizing and Measuring Economic Resilience, University of Malta Economics Department Working Paper, 2006

[74] Iordan M, (coord.). Performance. Sustainability - A Multidimensional Perspective, Part I, Romanian Academy, IPE, INCE, Bucharest, Romania; 2015, manuscript 
[75] Davies S. Regional Resilience in the 2008-2010 Downturn: Comparative Evidence from European Countries. Cambridge Journal of Regions, Economy and Society; 2011(4):369-382

[76] Iordan M, (coord.), Performance. Sustainability - A Multidimensional Perspective, Part II, Romanian Academy, IPE, INCE, Bucharest, Romania; 2016, manuscript

[77] Duschl M. Regional Resilience and Fat Tails: A Stochastic Analysis of Firm Growth Rate Distributions of German Regions, Working Papers on Innovation and Space 01. Philipps-Universität Marburg, Germany; 2014

[78] Iordan M, (coord.), Coeziunea economico-sociala a Romaniei in perspectiva Strategiei Europa 2020, IPE, INCE, Bucharest, Romania; 2014, manuscript

[79] Martin P, Mayer T, Mayneris F. Are Clusters More Resilient in Crises? Evidence from French Exporters in 2008-2009, London, CEPR Discussion Paper, No 9667, 2013

[80] Martin R, Sunley P, Tyler P. Local growth evolutions: Recession, resilience and recovery. Cambridge Journal of Regions, Economy and Society. 2015;8(2):141-148

[81] Martin RL, Sunley PJ. On the notion of regional economic resilience: conceptualisation and explanation. Journal of Economic Geography. 2015;15:1-42

[82] Crescenzi R, Rodríguez-Pose A. Innovation and Regional Growth in the European Union. Springer-Verlag Berlin Heidelberg, Germany; 2011

[83] Sala-i-Martin X. Regional cohesion: Evidence and theories of regional growth and convergence. European Economic Review. 1996;40:1325-1352

[84] Monfort P. Convergence of EU Regions. Measures and Evolution, Working Papers, 2008, No. 1, European Union Regional Policy

[85] Halmai P, Vasary V. Nominal and real convergence in the new member states (longerterm perspective). Bulletin of the Transilvania University of Braşov, Series V: Economic Sciences. 2011;4(53):193-220

[86] Albu LL. The convergence process in the EU estimated by Gini coefficients. Romanian Journal of Economic Forecasting. 2012;4:5-16

[87] Tselios V. Growth and convergence in income per capita and income inequality in the regions of the EU. Spatial Economic Analysis. 2009;4:347-370

[88] Miron D, Dima A, Păun C. A Model for Assessing Romania's Real Convergence Based on Distances and Clusters Method. Munich Personal RePEc Archive MPRA, 2009, Paper no. 31410

[89] Iordan M, Ghizdeanu I, Tapu D. Romania - Between the real convergence aim and the reality of territorial concentration of the economic development Strategii Manageriale/ Management Strategies, 2014, Universitatea "Constantin Brâncoveanu", Piteşti, Editura Independența Economică, VII1, ISSN 1844-668X, pp. 50-63

[90] Albu LL. Trends in Real Convergence and Structural Changes in EU, Project "Increasing the contribution of foreign trade to achieving real convergence", Strengthening the 
institutional capacity for evaluation and formulation of macroeconomic policies for economic convergence with EU within the National Commission for Prognosis - SMIS code 27153 - project co-financed by the European Social Fund through PODCA - Operational Programme for Administrative Capacity Development, 2013

[91] Iancu A. Real Convergence and Integration, Working Papers of National Institute of Economic Research, 090102. National Institute of Economic Research; 2009

[92] Răileanu Szeles M, Marinescu N. Real convergence in the CEECs, euro area accession and the Role of Romania. The European Journal of Comparative Economics. 2010;7(1):181-202

[93] Miron D, Tatomir F, Alexe I. Do Central and Eastern European Countries become more similar in terms of sectoral structures as their real convergence with the Euro Area increases? Analysis on the last decade. Economic Computation \& Economic Cybernetics Studies \& Research. 2013;47(1):5-26

[94] Simionescu M. The Assessment of Income Convergence Hypothesis in Romanian Counties Using the Panel Root Approach. Vol. 2. Studia Universitatis Babes BolyaiOeconomica; 2014. p. 57-67

[95] Landesmann M, Römisch R. Economic Growth, Regional Disparities and Employment in the EU-27. Vienna. WIIW Research Report 333; 2006

[96] Carrington A. Regional convergence in the European Union: A stochastic dominance approach. International Regional Science Review. January 2006;29(1):64-80

[97] Ezcurra R, Pascual P, Rapun M. Spatial disparities in the European Union: An analysis of regional polarization. Annals of Regional Science. 2007;41:401-429

[98] Melchior A. Regional Inequality and Convergence in Europe, 1995-2005, CASE Network Studies and Analyses No. 374, 2008

[99] Enflo KS. Productivity and employment-Is there a trade-off? Comparing Western European regions and American states 1950-2000. Annals of Regional Science. 2010; 45:401-421

[100] Dobrinsky R, Havlik P. Economic Convergence and Structural Change: the Role of Transition and EU Accession, WIIW Research Report 395, July 2014

[101] Iordan M, Chilian MN. Dynamics of Real and Structural Convergence at Sub-regional Level in Romania, Proceedings of the 3rd International Conference 'Economic Scientific Research - Theoretical, Empirical and Practical Approaches', ESPERA 2015. Bucharest, Romania: Peter Lang Publishing House; December 3-4, 2015

[102] Rozmahel P, Kouba L, Grochova L, Najman N. Integration of Central and Eastern European Countries: Increasing EU Heterogeneity? WWW for Europe Policy Paper No. 9 June 2013

[103] Firgo M, Huber P. Unconditional Convergence in Currency Unions: An Analysis of European Regions from 1991 to 2009, WWW for Europe Policy Paper No. 4, June 2013 
[104] Petrakos G, Artelaris P. European regional convergence revisited: A weighted least squares approach. Growth and Change. 2009;40:319-331

[105] Petrakos G, Artelaris P. Intraregional spatial inequalities and regional income level in the European Union: Beyond the inverted-U hypothesis. International Regional Science Review. 2016;39(3):291-317

[106] European Commission.ANewPartnershipforCohesion:Convergence, Competitiveness, Cooperation, Third Report on Economic and Social Cohesion. Luxembourg: Office for Official Publications of the European Communities; 2004

[107] European Commission. Growing Regions, Growing Europe, Fourth Report on Economic and Social Cohesion. Luxembourg: Office for Official Publications of the European Communities; 2007

[108] European Commission. Investing in Europe's Future, Fifth Report on Economic, Social and Territorial Cohesion. Luxembourg: Office for Official Publications of the European Communities; 2010

[109] Rodriguez-Pose A, Tselios V. Toward inclusive growth: Is there regional convergence in social welfare? International Regional Science Review. 2015;38(1):30-60

[110] Iordan M, Chilian MN. The sectoral structures in Romania, its regions and the EU countries - Key features of economic and social cohesion. In: Procedia Economics and Finance. Vol. 8, pp. 397-406, Elsevier B.V., Amsterdam, The Netherlands; 2014

[111] Chilian MN, Iordan M, Pauna CB. Real and structural convergence in the Romanian counties in the pre-accession and post-accession periods, 56th ERSA Congress, Cities \& Regions: Smart, Sustainable, Inclusive? Vienna, August 23-26,2016

[112] Antonescu D. Measuring regional convergence - An application to the European Union and Romania. Revista Economică. 2012;Supplement No. 1:46-59

[113] Ghizdeanu I, Iordan M, Chilian MN, Țapu D. Real convergence in the Romanian regions in the period of post-accession to the European Union. In: The Tenth Edition of the International Conference on Theoretical and Applied Economic Practices "Economic Growth in Conditions of Globalization". Chisinau, Republic of Moldova: National Institute for Economic Research; October 15-16, 2015

[114] Longhi C, Musolesi A. European cities in the process of economic integration: Towards structural convergence. Annals of Regional Science. 2007;41:333-351

[115] Bickenbach F, Bode E. Disproportionality measures of concentration, specialization, and localization. International Regional Science Review. October 2008;31(4):359-388

[116] Dobrescu E. Sectoral structure and economic growth. Romanian Journal of Economic Forecasting. 2013;3:5-36

[117] Kallioras D, Petrakos G. Industrial growth, economic integration and structural change: Evidence from the EU new member-states regions. Annals of Regional Science. 2010;45:667-680 
[118] Havlik P. Patterns of Structural Change in the New EU Member States, WIIW Research Report 394, April 2014

[119] Zaman G, Goschin Z. Economic downfall and speed of recovery in Romanian counties. A Spatial Autoregressive Model, Economic Computation and Economic Cybernetics Studies and Research. 2015;49(3):21-40 
